\title{
Regression Analysis and Indoor Air Temperature Model of Greenhouse in Northern Dry and Cold Regions
}

\author{
Ting Zhao and Heru Xue \\ College of computer \& information Engineering, Inner Mongolia Agricultural University, \\ Hohhot, Inner Mongolia, P. R. China \\ simadoudou@gmail.com
}

\begin{abstract}
The indoor air temperature of greenhouse is an important parameter in environmental monitoring. Existing research on it has many, and the mathematical models have been made. But the obtained models do not apply to the northern areas features of dry and cold. On the basis of previous studies, the indoor air temperature model of greenhouse will be re-modeling by using the regression analysis method in this paper. Analysis each convection heat transfer coefficient of the model and re-established them. In the case of known the outdoor weather conditions, the solution of the indoor temperature will be implemented by using the computer programming. And the data of a period is selected randomly from the observational data to validate the model is feasible and applied.
\end{abstract}

Keywords: Indoor air temperature model, Regression analysis method, Model parameters, Computer programming.

\section{Introduction}

There are many advantages in China's light greenhouse, but the environmental control level of greenhouse is still lower. The artificial experience is still the main force, and theoretical and practical guidance is lacking. The indoor air temperature of greenhouse is an important parameter in environmental monitoring. Predecessors have done a lot of research on the prediction model of the indoor air temperature of greenhouse. But most studies have been done for the greenhouse in Beijing. [1, 2]And the obtained models do not apply to the northern areas features of dry and cold.

The prediction model of the indoor air temperature of greenhouse which can be used in the northern areas features of dry and cold can predict the daily change of temperature with time. According to forecasts, the staff can regulate the temperature actively, so that the crops can be provided the best growth temperatures.

The model to be build up on the basis of previous' work, and the indoor air temperature model of greenhouse will be re-modeling by using the regression analysis method. Analysis each convection heat transfer coefficient of the model and re-established them. The typical areas and typical greenhouse will be chosen for the study. And using the known conditions to validate the model is feasible and applied. 


\section{The Indoor Air Temperature Model of Greenhouse}

Table 1. Sign Description

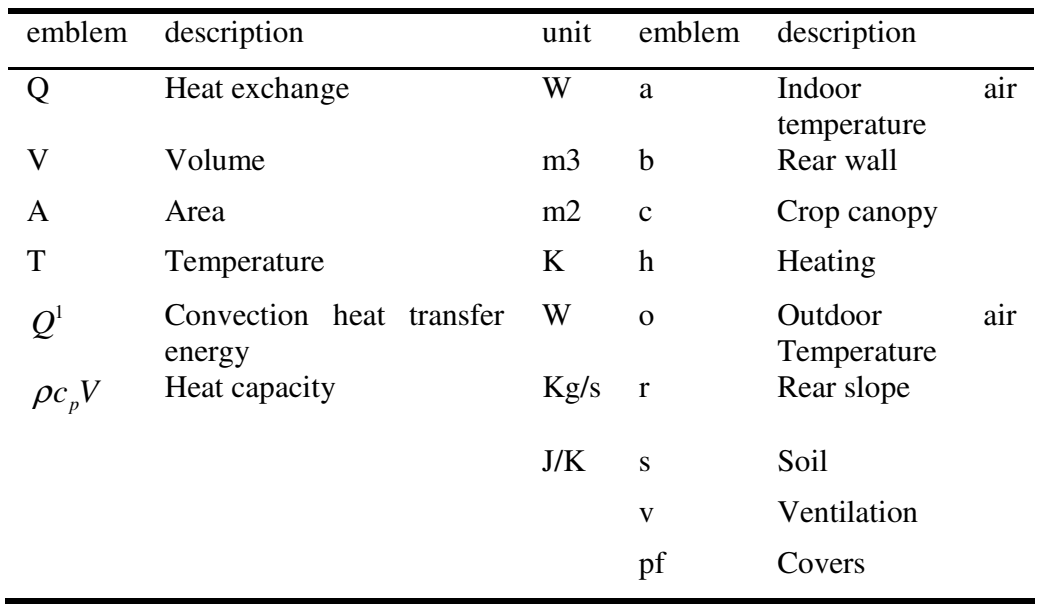

\subsection{Heat Balance Differential Equation of Indoor Air Temperature}

The heat balance differential equation used in this paper mainly by heat conduction differential equation. The model conditions have been simplified some. And according to the heat transfer principles and the law of conservation of mass and energy, the physical processes in the greenhouse have been considered comprehensively. The thermal change has much effect on thermal environment of greenhouse caused by heat change and moisture variation which come from solar radiation, heat convection, radiation heat transfer, heat exchange and natural ventilation. [3, 4]

$$
\rho{ }_{a} \mathrm{c}_{p a} \mathrm{v}_{a} \times \frac{\mathrm{dT}_{a}}{\mathrm{dt}_{0}}=\mathrm{Q}_{h}-\mathrm{Q}_{b}^{1}-\mathrm{Q}_{r}^{1}-\mathrm{Q}_{s}^{1}-\mathrm{Q}_{p f}^{1}-\mathrm{Q}_{c}^{1}-\mathrm{Q}_{V}
$$

On the left of the equation is the heat change caused by the air temperature changes with time. And the right contains the energy of the indoor air temperature coming from hot-water heating-- $Q_{h}$; the energy of the indoor air temperature wasted by natural ventilation and infiltration heat loss-- $Q_{V}$; and the energy coming from natural-convection heat transfer-- $Q_{i}^{1}$.

This is the derived formula of the indoor air temperature changes with time.

$$
\mathrm{t}_{a}=\mathrm{t}_{a 0}+\Delta \mathrm{t}_{a}=\mathrm{t}_{a 0}+\frac{Q_{h}-Q_{b}^{1}-Q_{r}^{1}-Q_{s}^{1}-Q_{p f}^{1}-Q_{c}^{1}-Q_{V}}{\rho_{a} c_{p a} V_{a}} \Delta t
$$


Known by the Newton's law of cooling, the convection heat transfer energy from gas A to solid B can be shown as this.

$$
\mathrm{Q}_{\mathrm{A}-\mathrm{B}}^{1}=\mathrm{A}_{\mathrm{A}-\mathrm{B}} \alpha_{\mathrm{A}-\mathrm{B}}\left(\mathrm{T}_{\mathrm{A}}-\mathrm{T}_{B}\right)
$$

In this equation, $\mathrm{A}_{\mathrm{A}-\mathrm{B}}$ is the surface area of the heat transfer from $\mathrm{A}$ to $\mathrm{B} ; \alpha_{\mathrm{A}-\mathrm{B}}$ is the coefficient of the heat transfer between $A$ and $B ; T_{A}$ and $T_{B}$ is the temperature of $A$ and $\mathrm{B}$.

The indoor air is heated mainly by the hot-water heating pipes. And the heat transfer between heating pipes and the indoor air is carried out by convection.

The energy of the indoor air temperature coming from hot-water heating is $Q_{h}$. It can be shown as this.

$$
\mathrm{Q}_{h}=\mathrm{A}_{h} \mathrm{~h}_{h}\left(\mathrm{~T}_{p}-\mathrm{T}_{a}\right)
$$

In this equation, $A_{h}$ is the surface area of the hot-water heating pipes; $h_{h}$ is the coefficient of the heat transfer between the heating pipes and the indoor air; $\mathrm{T}_{p}$ is the temperature of the hot-water heating pipes; $\mathrm{T}_{a}$ is the indoor air temperature.

The energy of the indoor air temperature wasted by natural ventilation and infiltration heat loss is $Q_{V}$. It can be shown as this.

$$
\mathrm{Q}_{V}=\rho_{a} \mathrm{c}_{a} \Phi_{V}\left(\mathrm{~T}_{a}-\mathrm{T}_{o}\right)
$$

In this equation, $\Phi_{V}$ is the air quantity of the indoor air; $\rho_{a} c_{p a}$ is the specific heat volume of the indoor air; $\mathrm{T}_{a}$ is the indoor air temperature; $\mathrm{T}_{o}$ is the outdoor air temperature.

Through the equations of (2),(3),(4), and (5), the heat balance differential equation of indoor air temperature can be simplified as this.

$$
\begin{aligned}
& \frac{\left(\mathrm{T}_{a}-\mathrm{T}_{0}\right) \rho_{a} \mathrm{c}_{p a} \mathrm{~V}_{a}}{\Delta \mathrm{T}} \\
& =\mathrm{A}_{h} \mathrm{~h}_{h}\left(\mathrm{~T}_{a}-\mathrm{T}_{h}\right)-\mathrm{A}_{b} \alpha_{a-b}\left(\mathrm{~T}_{a}-\mathrm{T}_{b}\right)-\mathrm{A}_{r} \alpha_{a-r}\left(\mathrm{~T}_{a}-\mathrm{T}_{r}\right)-\mathrm{A}_{s} \alpha_{a-s}\left(\mathrm{~T}_{a}-\mathrm{T}_{s}\right) \\
& -\mathrm{A}_{p f} \alpha_{p f}\left(\mathrm{~T}_{a}-\mathrm{T}_{p f}\right)-\mathrm{A}_{c} \alpha_{a-c}\left(\mathrm{~T}_{a}-\mathrm{T}_{c}\right)-\rho_{a} \mathrm{c}_{p a} \Phi_{v}\left(\mathrm{~T}_{a}-\mathrm{T}_{o}\right)
\end{aligned}
$$

\subsection{Heat Convection Coefficient-- $\alpha_{\mathrm{i}}$}

Heat convection is the heat transfer which happened on the liquid flows through the solid surface. In the greenhouse which has the small natural ventilation, rising or declining the indoor air temperature is mainly through the heat convection with the cover, the ground soil, plants and other heat transfer to achieve.

There are many essays about the heat convection in overseas. And the studies in this respect are also very mature. The arithmetic in these studies can be used in our country greenhouse. The heat convection coefficient can be shown as this. [5] 


$$
\alpha=\mathrm{h}\left(\mathrm{T}_{\mathrm{i}}-\mathrm{T}_{j}\right)^{\beta} \quad \beta=5 / 4
$$

Based on such expression of the heat convection, each heat convection coefficient of the heat balance differential equations can be explained to $h\left|\mathrm{~T}_{\mathrm{i}}-\mathrm{T}_{j}\right|^{0.25}$.

Therefore, the problem of optimizing the equation is the problem of calculating the value of $h$.

\section{Known Conditions of This Model}

\subsection{Structural Parameters}

To facilitate the calculation, the greenhouse structure can be approximately regarded as the following graphic which does not affect the results on the premise.

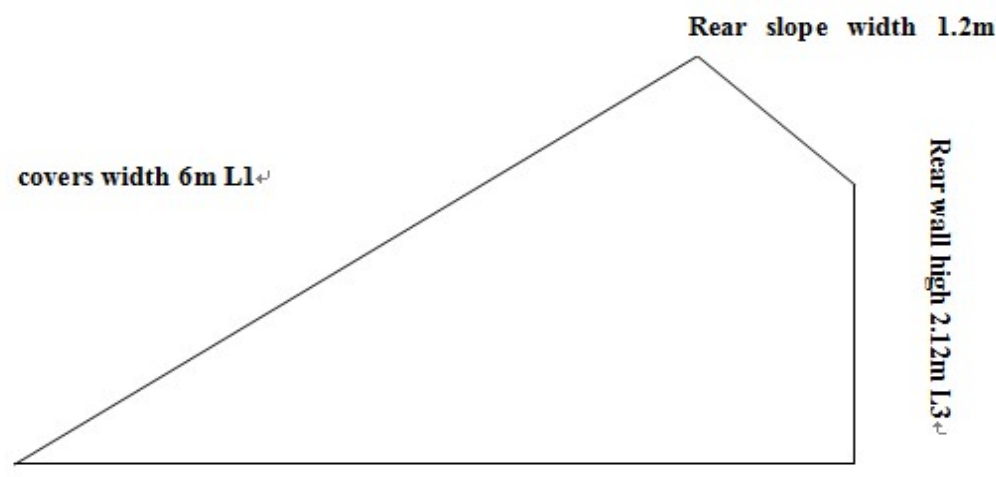

Indoor span $6.5 \mathrm{~m} \mathrm{L4}$

- The length of the greenhouse $\mathrm{L} 5=50(\mathrm{~m})$

- Leaf area index of the indoor crops $\mathrm{La}=0.3$

- The area of the covers L1*L5

- The area of the ground L4*L5

- The area of the rear slope L2*L5

- The area of the rear wall L3*L5

- The area of the crop canopy $\mathrm{L} 4 * \mathrm{~L} 5 * \mathrm{La}$

- The volume of the indoor air $\mathrm{V}=506$

- The specific heat volume of the indoor air $\rho_{a} \mathrm{C}_{p a}=1185 ; \mathrm{kJ} /\left(\mathrm{kg} \cdot{ }^{\circ} \mathrm{C}\right)$

- The temperature of the heating pipes during the day $\mathrm{T}=60+273$; $(\mathrm{K})$

- The area of the heating pipes is $9 \mathrm{~m}^{\wedge} 2$

- The coefficient of the heat transfer between the heating pipes and the indoor air $1.95 *\left(\mathrm{~T}_{\text {空气 }}-\mathrm{T}_{\text {管内水 }}\right)^{0.39}$.

- The air quantity of the indoor air $\Phi=0.001 * \mathrm{~V} / 3600$ 


\subsection{Known Conditions (Temperature Indicators)}

1) The 24-hour predicted values come from the weather forecast. They include the outdoor air temperature, the outdoor humidity, the wind velocity, the wind direction and the uitraviolet intensity.

2) Each average of the data calculated by hour is obtained. And the data of the cover temperature, the soil temperature, the rear wall temperature, the rear slope temperature, the crop canopy temperature and indoor air temperature is detected by the greenhouse monitoring system.

\section{Model Validation}

Experimental data is the observed data which can stand for the northern areas features of dry and cold. Use nonlinear regression analysis to optimize the parameters which comes from this heat balance differential equation of indoor air temperature. Nonlinear regression analysis is using least square method to estimate the parameters of non-linear model. Formula six is used to the regression equation of non-linear model. The starting value of the parameter $h$ chose the empirical value 1.25.The sample data chose the data from November and December of 2009 and January and February of 2010. Other required temperature used the observed data. Each heat transfer coefficient of the model was re-established by using SAS software.

November 23 to 30, 2009 and January 1 to 6, 2010 is the tested date. And the forecasting module of the indoor air temperature has been verified by using these data. The two pictures below are the comparison diagram of predicted values and measured values using MATLAB subroutine to output.

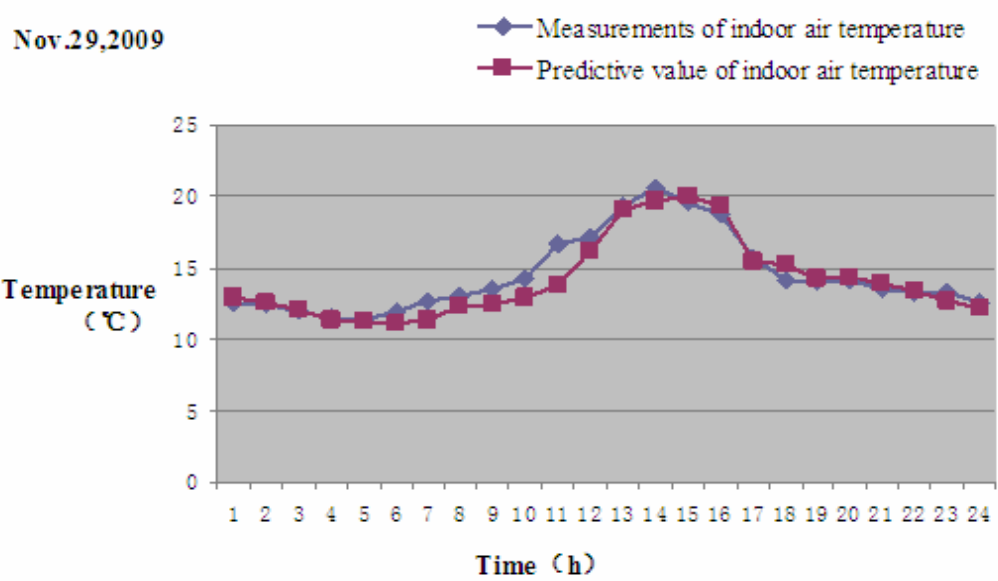

Fig. 1. The test and prediction data inside air temperature of the solar greenhouse 
Jan.2,2010

$\rightarrow$ Measurements of indoor air temperature Pre dictive value of indoor air temperature

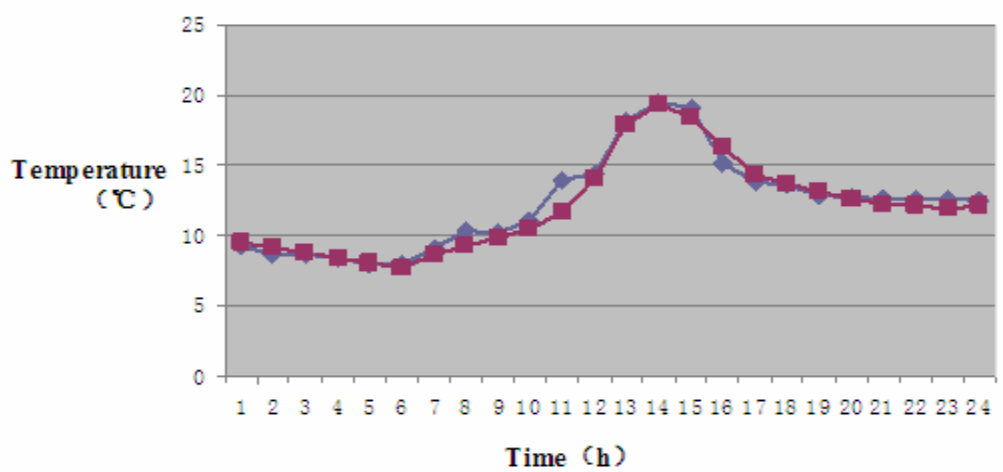

Fig. 2. The test and prediction data inside air temperature of the solar greenhouse

Table 2. The test and prediction data indoor air temperature of the greenhouse Jan.2,2010

\begin{tabular}{lllllllll}
\hline & 0 & 1 & 2 & 3 & 4 & 5 & 6 & 7 \\
\hline Predictive value & 9.5 & 9.1 & 8.8 & 8.4 & 8.1 & 7.7 & 8.7 & 9.3 \\
Measurements & 9.3 & 8.7 & 8.6 & 8.4 & 7.9 & 7.9 & 9.1 & 10.3 \\
\hline & 8 & 9 & 10 & 11 & 12 & 13 & 14 & 15 \\
\hline Predictive value & 9.8 & 10.2 & 11.1 & 13.6 & 16.9 & 19.3 & 18.4 & 16.4 \\
Measurements & 10.8 & 12.2 & 13.9 & 14.4 & 18.2 & 19.5 & 19.1 & 15.2 \\
\hline & 16 & 17 & 18 & 19 & 20 & 21 & 22 & 23 \\
\hline Predictive value & 14.3 & 13.7 & 13.1 & 12.6 & 12.3 & 12.1 & 11.9 & 12.1 \\
Measurements & 13.8 & 13.6 & 12.9 & 12.7 & 12.6 & 12.6 & 12.6 & 12.5 \\
\hline
\end{tabular}

\subsection{Interpretation of Result}

Validation data used the data of the weather including sunny, cloudy and cloudy. Diagram one and diagram two shows that the variation trend with time of predicted values and measured values is consistent. And the temperature contrast between predicted values and measured values is small. The average relative error is less than $10 \%$. Therefore, the simulation results which calculated by the mathematical model of are reliable.

The two diagrams also show that the maximum between predicted values and measured values present to 9 o'clock and 10 o'clock after lifting up the quilt used to keep warm. Because the solar radiation light into the indoor, the indoor air temperature shoot up. But this prediction model cannot predict it. So this is the model should be improved. 


\section{Conclusion}

The rebuilding heat transfer coefficients apply to the northern areas features of dry and cold. So the prediction model of indoor air temperature is feasible and applied. But the values predicted are not good after lifting up the quilt. And the problem will be studied next.

\section{References}

1. Sun, F.: Simulation and Analysis of Direct Light Environment in Typical Greenhouse in Beijing- Light Simulation and Analysis Facility Agriculture Research 4. Agricultural Engineering 9(2), 45-51 (1993)

2. Liu, H., Gou, W., Li, H.: Light Environment Simulation and Analysis of Greenhouse in Beijing. Journal of Applied Meteorology 19(3), 350-355 (2008)

3. Li, W., Dong, R., Tang, C., Zhang, S.: Theoretical Model of Thermal Environment in SolarPlastic Greenhouses with One-Slope. Transactions of the CSAE 5(3), 160-163 (1997)

4. Chen, Q., Wang, Z.: Dynamic Simulation of Thermal Environment in Solar Greenhouse 1(1), 67-72 (1996)

5. Li, X.: Mathematical Simulation and Structural Optimization of Greenhouse Thermal Environment. China Agricultural University (2005)

6. Meng, L.: Thermal Environment Model in Chinese Solar Greenhouse Based on VB and MATLAB and Structure Optimization. Chinese Academy of Agricultural Sciences (2008)

7. Wu, C., Zhao, X., Guo, L.: Simulation and Analysis of Greenhouse Crop Thermal Environment. Agricultural Engineering 23(4), 190-195 (2007)

8. Xin, B., Qiao, X., Teng, G.: Construction of Greenhouse Environmental Prediction Model. Agricultural Research 4(2), 96-100 (2006)

9. Wang, G., Kang, G.: Regression and Analysis of Greenhouse Environment. Beijing Agricultural College 9(2), 75-84 (1994)

10. van Ooteghem, R.J.C.: Optimal Control Design for a Solar Greenhouse. CIP gegevens Koninklijke Bibliotheek, Den Haag (2007)

11. Korner, O., Challa, H., van Ooteghem, R.J.C.: Crop based climate regimes for energy saving in greenhouse cultivation. Wageningen University, Wageningen (2003) 